Научная статья

УДК 338.439

DOI 10.18101/2304-4446-2021-4-70-75

\title{
ОЦЕНКА ПРОДОВОЛЬСТВЕННОЙ САМООБЕСПЕЧЕННОСТИ НАСЕЛЕНИЯ РЕГИОНА
}

\author{
(C) Колесняк Антонина Александровна \\ доктор экономических наук, профессор, \\ Красноярский государственный аграрный университет \\ Россия, 660049, г. Красноярск, пр-т Мира, 90 \\ kolesnyak.antonina@yandex.ru
}

\begin{abstract}
Аннотация. Полноценное продовольственное обеспечение регионов и повышение уровня продовольственной безопасности государства являются важнейшими условиями выживания и устойчивого социально-экономического развития любой страны. При этом стратегическое значение имеет самообеспеченность населения продовольствием. В статье выполнена оценка самообеспеченности жителей Красноярского края основными продуктами питания в сравнении с общероссийскими показателями. Выявлено, что в исследуемом регионе душевое производство значимых пищевых продуктов существенно ниже установленных рациональных норм и уровень продовольственной самообеспеченности очень низкий. Рассмотрены стоимостные и физические параметры валового производства сельскохозяйственной продукции в регионе. Обозначены концептуальные направления повышения продовольственной самообеспеченности населения региона. Результаты исследования имеют определенную аналитическую значимость для организации и управления региональной системой продовольственного обеспечения.

Ключевые слова: продовольственное обеспечение, продовольственная безопасность, самообеспеченность, регион, управление, система, производство, сельское хозяйство, оценка.
\end{abstract}

\section{Для цитирования}

Колесняк А. А. Оценка продовольственной самообеспеченности населения региона // Вестник Бурятского государственного университета. Экономика и менеджмент. 2021. № 4. С. 70-75.

Продовольственная проблема в последние несколько десятилетий, особенно по мере роста населения планеты, заметно обострилась. Сложность и многогранность продовольственной проблемы вызывают устойчивый интерес со стороны многих исследователей, каждый из которых в определенной мере рассматривает отдельные аспекты данной проблемы [1; 2; 6-10 и др.].

Продовольствие является существенным элементом жизнеобеспечения людей, при этом качественный и количественный состав пищевых продуктов определяет состояние здоровья нации. Поэтому каждый регион России должен по возможности стремиться в максимальной степени обеспечивать население подведомственной территории продовольствием за счет собственного производства [4].

Для любого государства всегда актуальными были и остаются вопросы регулирования системы продовольственного обеспечения. Санкции со стороны США и европейских стран в адрес России, а также COVID-19 внесли свои вызовы в эту 
систему. Отмечается, что «экономическая нестабильность на мировом продовольственном рынке связана с действиями правительств многих стран по введению ограничительных мер, по перемещению продуктовых потоков и населения, работающего в этой сфере» [3]. Поэтому в стране стратегически важно обеспечить стабильное развитие аграрной сферы, в том числе посредством целенаправленного ее госрегулирования и поддержки [5].

В январе 2020 г. в Российской Федерации была принята новая национальная Доктрина продовольственной безопасности ${ }^{1}$ (Доктрина-2020), где отдельно обозначены подходы к оценке самообеспечения страны основными видами продуктов питания (пп. 2, 8, 9 Доктрины-2020). Однако и на региональном уровне в контексте достижения устойчивого социально-экономического развития проблема продовольственного обеспечения не менее актуальна, чем на общенациональном уровне. Именно на региональном уровне конкретно проявляются реальные параметры физической и экономической доступности продовольствия. Одним из условий доступности продовольствия является уровень продовольственного самообеспечения.

Уровень продовольственного самообеспечения (самообеспеченность) регионов определяется отношением объемов собственного (регионального) производства продуктов питания к их рациональным нормам (табл. 1).

Таблица 1

Самообеспеченность населения продовольствием

\begin{tabular}{|c|c|c|c|c|}
\hline \multirow[t]{3}{*}{ Пищевые продукты } & \multicolumn{4}{|c|}{ На начало 2020 г. } \\
\hline & \multicolumn{2}{|c|}{$\begin{array}{c}\text { Душевое производство, } \\
\text { кг в год }\end{array}$} & \multicolumn{2}{|c|}{$\begin{array}{c}\text { Самообеспеченность, } \\
\%\end{array}$} \\
\hline & $\begin{array}{r}\text { Российская } \\
\text { Федерация }\end{array}$ & $\begin{array}{l}\text { Красноярский } \\
\text { край }\end{array}$ & $\begin{array}{l}\text { Российская } \\
\text { Федерация }\end{array}$ & $\begin{array}{l}\text { Красноярский } \\
\text { край }\end{array}$ \\
\hline Хлебные продукты & 839 & 761 & 874,0 & 792,7 \\
\hline Картофель & 153 & 234 & 170,0 & 260,0 \\
\hline Мясо и мясопродукты & 75 & 45 & 102,7 & 61,6 \\
\hline $\begin{array}{l}\text { Молоко и молочные } \\
\text { продукты }\end{array}$ & 214 & 224 & 65,8 & 68,9 \\
\hline Овощи и бахчевые & 93 & 55 & 66,4 & 39,3 \\
\hline Яйца, штук & 306 & 298 & 117,7 & 114,6 \\
\hline Caxap & 75 & 0 & 712,5 & 0,0 \\
\hline Масло растительное & 35,5 & 0,2 & 240,8 & 1,7 \\
\hline
\end{tabular}

Рассчитано автором на основе источников ${ }^{2}$

Самообеспеченность как индикатор позволяет оценить способность региона удовлетворить потребности населения в продуктах питания для жизнеобеспечения в требуемом объеме независимо от внешних факторов.

\footnotetext{
${ }^{1}$ Об утверждении Доктрины продовольственной безопасности РФ: указ Президента РФ от 21.01.2020 № 20 .

2 Об утверждении рекомендаций по рациональным нормам потребления пищевых продуктов, отвечающих современным требованиям здорового питания: приказ Минздрава России от 19.08.2016 № 614 (ред. от 01.12.2020); Регионы России. Социальноэкономические показатели. 2020: стат. сб. / Росстат. Москва, 2020. 1242 с.
} 
Если в целом по России почти по всем продуктам, кроме молока и овощей, к началу 2020 г. была достигнута полная самообеспеченность и даже перепроизводство, то в Красноярском крае положение отличается: полная (даже избыточная) самообеспеченность сложилась всего по трем продуктам - хлебу, картофелю и яйцам, остальными же продуктами регион обеспечен не в полной мере. Так, собственное производство молочной продукции обеспечивает жителям рациональное потребление лишь на 68,9\%, мясных продуктов - на 61,6\%, овощей и бахчевых - на 39,3\%, растительного масла — на 1,7\%, сахара — на 0\%. Дефицит указанных продуктов восполняется их ввозом из других регионов.

Вместе с тем с медицинской точки зрения для поддержания здоровья в пищевом рационе человека в рекомендованном объеме обязательно должны потребляться белковосодержащие продукты (мясные и молочные), а также клетчатка и витамины (овощи и бахчевые). Поэтому подчеркнем, что на регионы возлагается ответственность по достижению максимально полной самообеспеченности основными продуктами питания.

В Красноярском крае душевое производство значимых пищевых продуктов существенно ниже установленных рациональных норм и уровень самообеспеченности очень низкий. Самообеспеченность продовольствием в регионах зависит от множества природно-климатических и социально-экономических факторов. Если для выращивания сахарной свеклы и подсолнечника природные условия в данном регионе крайне неблагоприятны, то производство мясных, молочных продуктов и овощей при использовании адаптированных технологий и соблюдении научно обоснованных рекомендаций способно повысить самообеспеченность этими продуктами.

Изучение динамики стоимостного объема валовой сельскохозяйственной продукции Красноярского края позволяет наблюдать неоднозначную тенденцию (табл. 2).

Таблица 2

Производство сельскохозяйственной продукции в хозяйствах всех категорий, в фактически действовавших ценах

\begin{tabular}{|l|c|c|c|c|c|c|c|c|}
\hline \multicolumn{1}{|c|}{ Регион } & \multicolumn{7}{|c|}{ На начало года: } \\
\cline { 2 - 9 } & 2006 & 2011 & 2015 & 2016 & 2017 & 2018 & 2019 & 2020 \\
\hline $\begin{array}{l}\text { Краснояр- } \\
\text { ский край: } \\
\begin{array}{l}\text { млн р. } \\
\text { \% к Россий- } \\
\text { ской Феде- } \\
\text { рации }\end{array}\end{array}$ & 21037 & 56408 & 66302 & 76204 & 80983 & 71935 & 77914 & 84865 \\
\hline $\begin{array}{l}\text { Российская } \\
\text { Федерация, } \\
\text { млн р. }\end{array}$ & 1380961 & 2462187 & 4031064 & 4794615 & 5112356 & 5109475 & 5348803 & 5801410 \\
\hline
\end{tabular}

Составлено автором по источнику ${ }^{1}$

1 Регионы России. Социально-экономические показатели. 2020: стат. сб. / Росстат. Москва, 2020. 1242 с. 
В 2006-2017 гг. имел место планомерный рост параметров производства. За 2017-2018 гг. произошел некоторый спад, затем - ежегодный прирост. К началу 2020 г., с момента очередного сокращения (за последние четыре года), объем продукции сельского хозяйства возрос на $4,8 \%$.

Вклад Красноярского края в общероссийский объем производства продукции сельского хозяйства постепенно снижается. Изменение физического объема производства сельскохозяйственной продукции исследуемого региона также было неоднозначным (рис. 1). За 2011-2015 гг. и 2017-2018 гг. наблюдалось заметное снижение физических объемов производства, однако в последние годы наметился рост.

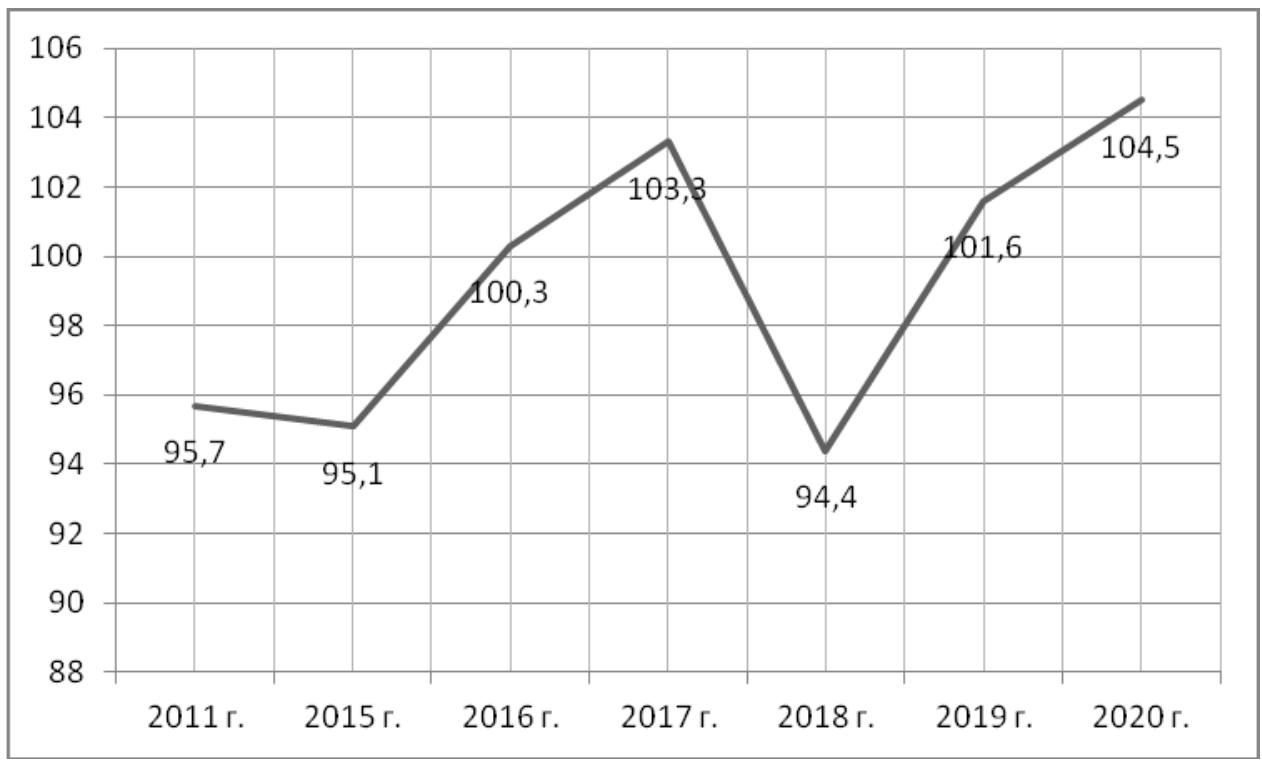

Рис. 1. Изменение объемов производства сельскохозяйственной продукции в сопоставимых ценах в хозяйствах всех категорий Красноярского края (\% к предыдущему периоду)

Для повышения доступности продовольствия в регионе необходима объективная оценка производственных возможностей аграрного сектора по обеспечению населения пищевыми продуктами и максимально возможному повышению самообеспеченности продовольствием. Ведь с сокращением собственного производства возрастает объем ввозимого в регион продовольствия, что в определенной степени вызывает некоторый отток финансовых ресурсов из оборота, способствует росту уровня безработицы, другим нежелательным социальноэкономическим последствиям. Поэтому продовольственное обеспечение в объеме, составе и структуре, необходимых и достаточных для нормального жизнеобеспечения, здорового физического и социального развития людей, остается важнейшей государственной задачей региональных органов власти.

Таким образом, основу продовольственной безопасности страны составляет продовольственное обеспечение отдельных ее регионов, в которых стратегически важна достаточная самообеспеченность основными продуктами питания. 
Самообеспеченность в некоторой мере можно повысить посредством использования той выручки, которая получена от реализации излишков товарной агропродукции и продукции других отраслей, на закупку и ввоз тех пищевых продуктов, которые экономически нецелесообразно или даже невозможно производить в этом регионе. В целом для повышения самообеспеченности продовольствием в регионе важно стремиться к более полному использованию всех факторов производства на основе интенсификации труда и внедрения ресурсосберегающих технологий.

\section{Литература}

1. Адуков Р. Х., Адукова А. Н. Продовольственная безопасность России: необходимость усиления социальной ориентированности государственного управления // Экономика, труд, управление в сельском хозяйстве. 2021. № 4(73). С. 90-99. Текст: непосредственный.

2. Алтухов А. И. Первоочередные меры по реализации новой доктрины продовольственной безопасности российской федерации // Экономика сельского хозяйства России. 2020. № 3. С. 2-10. Текст: непосредственный.

3. Дугина Е. Л., Доржиева Е. В., Гармаева Л. Б. Оценка состояния системы продовольственного обеспечения региона в условиях цифровой трансформации // Вестник Забайкальского государственного университета. 2021. Т. 27, № 5. С. 107-116. Текст: непосредственный.

4. Колесняк И. А., Колесняк А. А. Формирование и распределение ресурсов продовольствия в Красноярском крае // Вестник КрасГАУ. 2014. № 6. С. 21-27. Текст: непосредственный.

5. Kolesnyak A. A., Polyanskaya N. M., Naydanova E. B., Kolesnyak I. A. Agricultural development trends in Russia // IOP Conference Series: Earth and Environmental Science. III International Scientific Conference: AGRITECH-III-2020: Agribusiness, Environmental Engineering and Biotechnologies. Krasnoyarsk Science and Technology City Hall of the Russian Union of Scientific and Engineering Associations, 2020. C. 22015.

6. Naidanova E. B., Polyanskaya N. M. Provision of food security of a region based on the example of the Republic of Buryatia // Studies on Russian Economic Development. 2017. № 1. C. 52-59.

7. Стадник А. Т., Шелковников С. А., Лубкова Э. М. Концептуальные основы совершенствования взаимодействия субъектов системы продовольственного обеспечения промышленного региона // АПК: Экономика, управление. 2021. № 1. С. 43-48. Текст: непосредственный.

8. Шилова А. Э. Продовольственная самообеспеченность населения региона в современных условиях: проблемы оценки и направления повышения // Проблемы развития АПК региона. 2019. № 1(37). С. 149-155. Текст: непосредственный.

9. Шилова А. Э., Лубкова Э. М., Мазурова М. А. Нормативно-правовое регулирование категории «продовольственная безопасность» в Российской Федерации: от межнационального до национального уровня // Экономика и предпринимательство. 2017. № 41(81). С. 174-179. Текст: непосредственный.

10. Шилова А. Э., Лубкова Э. М. Продовольственное обеспечение региона и конкурентоспособность АПК (на примере Кемеровской области). Кемерово: Изд-во КузГТУ, 2018. 11 с. Текст: непосредственный.

Статья поступила в редакцию 21.09.2021; одобрена после рецензирования 29.10.2021; принята к публикации 01.11.2021 


\title{
ASSESSMENT OF FOOD SELF-SUFFICIENCY OF THE REGION'S POPULATION
}

\author{
Antonina A. Kolesnyak \\ Dr. Sci. (Econ.), Prof., \\ Krasnoyarsk State Agrarian University \\ 90 Mira Prospect, Krasnoyarsk 660049, Russia \\ kolesnyak.antonina@yandex.ru
}

Abstract. Adequate food supply of the regions and an increase in the level of food security are the most important conditions for the survival and sustainable socio-economic development of any country. At the same time, food self-sufficiency of the population is of strategic importance. The article analyzes the staple food self-sufficiency of the residents of Krasnoyarsk Krai in comparison with such indicators for the country as a whole. It has been revealed that per capita production of staple food in the region under study is significantly lower than the established rational norms, and the level of food self-sufficiency is very low. We have considered the cost and physical parameters of gross agricultural production in the region, defined the conceptual directions of increasing food self-sufficiency of the region's population. The results of our research have a certain analytical significance for the organization and management of the regional food supply system.

Keywords: food supply, food security, self-sufficiency, region, management, system, production, agriculture, assessment.

\section{For citation}

Kolesnyak A. A. Assessment of Food Self-Sufficiency of the Region's Population. Bulletin of Buryat State University. Economy and Management. 2021; 4: $70-75$ (In Russ.).

The article was submitted 21.09.2021; approved after reviewing 29.10.2021; accepted for publication 01.11.2021. 